\title{
Research on the Status Quo of Long-term Rental Apartments in First-tier Cities in China and Its Countermeasures*
}

\author{
Liguang Zhao \\ School of Taxation \\ Jilin University of Finance and Economics \\ Changchun, China 130117
}

\author{
Mingju Liu \\ Yatai School of Business Administration \\ Jilin University of Finance and Economics \\ Changchun, China 130117
}

\author{
Nengyan Cheng \\ Yatai School of Business Administration \\ Jilin University of Finance and Economics \\ Changchun, China 130117
}

\begin{abstract}
This paper analyzes the development status and market prospects of long-term rental apartments in first-tier cities in China, and finds out the problems existing in the development of long-term rental apartments, hoping to solve these problems, help long-term rental apartments to develop better and solve the housing problems for migrants.
\end{abstract}

Keywords-Changbai Mountain North Scenic Area; tourism; sustainable development

\section{INTRODUCTION}

At present, China's social and economic development is rapid, but due to the differences in geographical locations and national policies, the regional development is obviously unbalanced. In the first-tier cities in China, because of their rapid economic development and high level of urbanization, there are a large number of employment opportunities and great personal development space. Therefore, for these firsttier cities with developed economies and large migrant populations, the housing problem has become an important problem hindering their development. In particular, the housing problems of employees in labor-intensive enterprises such as catering enterprises and star hotels have affected the security and social development of these cities. Therefore, the development of long-term rental apartments in first-tier cities in China has become the research focus of many scholars.

\section{THE DEFINITION OF LONG-TERM RENTAL APARTMENT}

The long-term rental apartment is an emerging apartment model in the market in recent years, which is mainly for migrant workers. They are renters and "second-hand landlords" that provide related services, but long-term rental

*Fund Project: The project of the National Natural Science Foundation of China (Project No.: 41401146); Jilin Province Science and Technology Development Plan Project (20150204040NY); Jilin Provincial Department of Education Project (JJKH20170140SK). apartments are different from traditional "second-hand landlords". At present, long-term rental apartments mainly include "white-collar apartments" and "enterprise apartments".

The traditional "long-term rental apartment" refers to the "white-collar apartment", also known as "single joint rent apartment". It is a new industry in the real estate three-tier market in recent years. It generally refers to that the developer rents the houses of the house owners, carries out centralized transformation according to a certain mode, puts some simple appliances in the houses, and provides related property services to attract white-collar workers working around. The lease term is usually from 3 months to a year. Corporate apartments are a new industrial sector of long-term rental apartments. The main difference between corporate apartments and traditional long-term rental apartments (white-collar apartments) lies in that the rental populations are different. Corporate apartments, also known as "blue-collar apartments" or "dormitory apartments", refer to that investors or real estate developers rent the houses of the house owners and transform the houses according to the model of college students' dormitories. There are usually $4-8$ beds in a room, and there is only simple furniture such as wardrobes. The apartments are rented out to labor-intensive businesses in the form of a whole lease for a minimum lease term of three months.

\section{THE DEVELOPMENT STATUS OF LONG-TERM RENTAL APARTMENTS IN FIRST-TIER CITIES IN CHINA AND THE INFLUENCING FACTORS}

\section{A. Overview of the Development of Long-term Rental Apartments}

In China, long-term rental apartments are still an emerging business opportunity. Currently, long-term rental apartments only account for $2 \%$ of the rental market, and the market's profit margin is about $4 \%$ for a long time. In the United States, Japan and other countries, institutional rentals account for 
$20 \%-30 \%$ of the rental market. Compared to them, the industry's development space in China is very broad. China's long-term rental apartments originated from the condition that real estate agents were entrusted by the house owners to rent out their houses. At the beginning, the real estate agents were entrusted by the owners to rent out their houses and charged the agency fee. Later, some real estate agents changed the sales mode of passively accepting the houses from the homeowners and renting them to the customers, they began to forwardly rent the houses from the owners and transform the houses. Regardless of whether the house is rented out to customers or not, it is necessary to pay the owner a certain amount of house use and management fees, and the real estate agent earns the price differences after renting the house to customers. At present, there are more than 500 apartment companies with considerable scales in China, and the number of apartment houses has exceeded 4 million. The market share of brand apartments has reached $2 \%$. Long-term rental apartments are mainly concentrated in the first-tier cities in China. Among them, there are long-term rental apartments with famous brands and considerable scales such as MoFang Apartment, Ziroom, YOU+,ANXIN,etc.

\section{B. Factors Affecting the Development of Long-term Rental Apartments}

1) Market: At present, China's social economic level is constantly improving, and the urbanization process is also accelerating. However, due to different geographical locations and national policies, the regional development is obviously unbalanced. In the first-tier cities in China with rapid economic development and high levels of urbanization, there are a large number of employment opportunities and large space for personal development. Therefore, China's first-tier cities such as Beijing, Shanghai, Guangzhou, and Shenzhen have large migrant populations. According to the 2016 statistics of the Bureau of Statistics, the number of permanent residents in Beijing, Shanghai, Guangzhou and Shenzhen was 21.73 million, 24.2 million, 14.04 million and 11.91 million respectively. At the end of 2016, the number of permanent migrant residents in Beijing, Shanghai, Guangzhou and Shenzhen was 8.08 million, 9.8 million, 5.34 million and 7.86 million respectively. At the same time, first-tier cities such as Beijing, Shanghai, and Guangzhou have high housing prices, which are unaffordable for most migrant workers. Renting a house is the best choice for these people. The demand in the rental market is strong, and the supplies of rental apartments fail to meet the demand. According to the "Leasing Market Research Report Series", in 2017, China has a total of 160 million people living in rented houses, and there is a need of about 53 million sets of rental apartments. However, there are only about 46 million sets of rental apartments currently, and the supply gap is obvious.

2) Society: In the traditional leasing communities, there are a lot of problems of residential houses, the fire safety facilities do not meet the standards, and the living environment is dirty and unsatisfactory, which cannot meet the tenants' demands for good service quality and living experience. The new urban workers are mostly university graduates who are born in the $80 \mathrm{~s}$ and $90 \mathrm{~s}$. It is required by them that the house they rent does not just have "a bed", but is a clean, comfortable home. At the same time, with the improvement of the social economic level and the advancement of culture, people's pursuit of self-happiness is getting higher and higher. In order to improve employee satisfaction and reduce employee turnover, companies are increasingly concerned about the accommodation environment of employees.

3) Policy: Due to the outstanding problems of private houses and the large number of floating population in China, the Chinese government encourages the development of longterm rental apartments. Especially in the first- and second-tier cities where the rental demand is strong, in order to encourage enterprises to rent apartments in a large-scale and professional manner, the state has granted preferential policies in taxation and land rent; clearly defined the rights and obligations of the lessor and the lessee, effectively protected the interests of tenants, encouraged the healthy development of long-term rental apartments and encouraged the lessor to sign long-term housing lease contracts with the lessees.

\section{THE PROBLEMS ENCOUNTERED IN THE DEVELOPMENT AND MANAGEMENT OF LONG-TERM RENTAL APARTMENTS}

\section{A. The Levels of Management and Service Are Uneven and the Management Systems Are Not Standardized}

China's long-term rental apartments have a short development time and a large development space. Many small enterprises and even private individuals have entered the industry, which makes the management and service level of the whole industry not high. Moreover, the number of branded long-term rental apartments is small, the development time of branded apartments is short, developers are still in the process of exploration of branded apartments, and the mature management system has not yet been established. Here we take MoFang Apartment as an example. MoFang Apartment is the first chain-type long-term rental apartment operator in China. It was established in 2009 in Shanghai, China. At present, in Beijing, Shanghai, Guangzhou, Shenzhen, Nanjing and other large- and medium-sized cities in China, there are direct-sale stores of MoFang Apartment. The number of stores has exceeded 100, and its business scale has ranked first in the industry. However, before May 2017, MoFang Apartment had been keeping accounts using the original manual billing method, and there was no formalized apartment transaction system installed, resulting in unclear accounts. Secondly, in order to rapidly increase market influence and occupy the market, MoFang Apartment began to expand its business from first-tier cities to second-tier cities in 2014. However, its lack of management in the choice of housing resources led to the closure of many stores in the later period. The location of the apartment depends only on the judgment of the founder or an individual. There is no perfect market report or regional analysis for reference, and only a visit by the visitor determines whether a place can be selected as the location of an apartment. For example, in 2017, the store of MoFang's No. 
9 Building Apartment in Shanghai's Linxin Road had to be closed because it was located in the industrial park.

\section{B. High Operating Costs and the Single Operating Model}

The operation mode of long-term rental apartments determines the high investment costs and long capital recovery period. China's long-term rental apartments are currently based on the "charter model" , that is, the apartment operator first signs a long-term rental contract with the house owner, then renovates the house and rents it again to customers to earn the price differences. This is the main way of revenue for the longterm rental apartment operators currently. However, the main source of profits for long-term rental apartment developers the price differences between the costs of the houses and the long-term rents of customers - is affected by many factors. At present, there are inadequate housing resources in the first-tier cities in China, resulting in the increase in the cost of houses. For example, in some old towns in Beijing and Shanghai, there are few buildings that can be used for living, and there are about $80 \%$ of the houses are used for self-living. Only less than $20 \%$ of the houses can be rented to customers in these places. And there are also some individual landlords, so the housing resources in these places are very inadequate, affecting the operating costs of the apartments. Secondly, in general, the cycle from getting the house, transforming it, to renting out it is the turnover rate of the house. In this cycle, the company has no revenue. Even if the renovation period has passed, if the apartment is not rented out, there will be a vacancy rate, which will not only bring no revenue, but also increase management and operating costs.

\section{Short Distribution Channels and High Marketing Expenses}

One of the common problems with these long-term rental apartments is that the distribution channels are short. Some low-end long-term rental apartment developers mainly publish rental information on platforms like 58.com. The relatively high-end long-term rental apartment developers release rental information through some intermediary stores, but the marketing costs of intermediary stores are also very high. For example, a new store of MoFang Apartment, which was established at the end of February 2018, spent 9,000 yuan to publish rental information on 58.com, but as of early April, the number of customers who had rented apartments on 58.com was 0 . Although the effect of cooperating with the intermediary is significant, the intermediary costs are too high. For example, like the room of 4,400 yuan a month, if the intermediary has sold more than 10 of such rooms, and the lease period reaches one year, the intermediary will charge a $30 \%$ commission for the long-term rental apartment developer. In addition, long-term rental apartment developers have to pay $10 \%$ commission to the relevant personnel. In this way, the developer only has $60 \%$ of the revenue. And removing the costs of the houses, the costs of personal management, etc., the long-term rental apartment is almost a loss-making business. Therefore, generally long-term rental apartment developers will not cooperate with the intermediary. Some long-term rental apartment developers gain extra income by expanding the scope of services, such as selling flowers in the lobby on Valentine's Day. But this did not have a substantial impact.

\section{Lack of Experienced Professional Enterprise Management Talents}

As the apartment industry is an emerging industry, there is a lack of professional and experienced management talents. Most of the current interior managements of the apartments come from real estate, hotel management and other industries, they are still in the stage of exploration and learning. Secondly, China's colleges and universities have not yet set up relevant majors and have not started to cultivate relevant talents.

\section{E. Limited Financing Channels Make the Development of the Industry Restricted}

At present, in China's long-term rental apartment market, there are few apartment developers using self-holding properties, and many apartment developers still use the form of charter. Although this can appropriately reduce the pressure on funds, the source of funds is single, and apartment developers still cannot escape the essence of "the second landlords". In recent years, apartment operators have entered the long-term rental apartment field mainly by introducing venture capital, privately placing funds, and increasing issues in stocks. Although there are many funds entering the market, there is great uncertainty in the entry and exit of funds, which is affected by the market. This type of investment is not conducive to the continuous and stable development of this emerging industry.

\section{LONG-TERM RENTAL APARTMENT DEVELOPMENT STRATEGIES}

\section{A. Establish a Unified Management System}

First, a standardized management system should be established. The government can raise the barriers to entry into the field and avoid the entry of unqualified companies, which will lead to the low level of the industry. Encourage the development of large-scale long-term rental apartment enterprises, form economies of scale and enhance brand influence. The company itself needs to develop a management system that is suitable for its current stage of development. Let management be standardized and rationalized, rather than in accordance with customary management models.

Establish an exit mechanism for investment institutions of apartment enterprises. Nowadays, the way in which an investment institution withdraws from an industry mainly includes merging, resales, and buy-backs. At present, the demand for long-term rental apartments in first-tier cities in China is large, and the barriers to enter the industry are low, so a large number of enterprises are pouring in the industry. However, due to the current single development model and profit model of long-term rental apartments in China, and due to the large capital investment and the long recycling period, general apartment enterprises will choose to withdraw from the long-term rental apartment market. The product and service standards of the apartment industry have not yet been established, and the long-term rental apartments with different brands have great differences, resulting in difficulty in 
integration and high cost of mergers and acquisitions. We can learn from the development experience of foreign countries and obtain low-cost funds through the issuance of REITs.

\section{B. Reasonably Reduce Operating Costs}

In view of the fact that China's long-term rental apartments have the single profit model, high operating costs and high investment risks, China's long-term rental apartment developers can learn from foreign operating models and flexibly combine long-term rent with short-term rent, which can make vacant houses be efficiently utilized, reduce the vacancy rate, improve the recovery rate of funds, and reduce the cost of vacancy management. In terms of after-sales services, long-term rental apartment providers can add additional personalized services in addition to providing basic facilities and services, provide full-process services for tenants, and achieve "apartment+" by integrating more businesses. For example, build a simple gym in the apartment, that is, achieve "apartment + fitness"; set up a simple kitchen inside the apartment, that is, achieve "apartment + dining" ; this "apartment +" mode can reduce the vacancy rate while generate a certain rental premium.

With the development of the Internet, the development of long-term rental apartments should be combined with the Internet to achieve informatization and intelligentization. A complete information service platform is indispensable for the operation of long-term rental apartments. This information service platform needs to run through the entire operation process - from the leasing in the previous period to the lease services in the later period, to achieve the combination of service and operation. In order to reduce the heavy workload of the operational background, and to provide full-process services, long-term rental apartment developers can use the market cooperation method to outsource some of the services of the apartment, such as the replacement of sheets and the collection of express deliveries. This "paying attention to services and taking less account of operations" management model can improve operational control efficiency, reduce operating expenses, and achieve profitable conversion.

\section{Looking for New Profit Models}

At present, the domestic profit models are mostly "rent price differences + value-added services". However, the main profit model of EQR is "appreciation in asset value + rent". The success of EQR also shows that this model has its own advantages. First, the appreciation of assets. First of all, the developer must optimize the investment portfolio, choose a location with good economic development, superior geographical position, and strong demand for renting apartments, and concentrate the house resources to obtain more asset appreciation income. In addition, constantly replace assets to improve the quality of assets, and look for opportunities for low-cost acquisitions. Second, the rent. Optimize the layout, reduce operating costs, and increase rental profitability.

\section{Expanding Talent Recruitment Channels}

First of all, the development time of domestic long-term rental apartments is short, and there is a lack of development experience and relevant talents with management experience. In order to solve these problems, long-term rental apartment developers can hire foreign management experts and learn from foreign development experience, but at the same time they should pay attention to the domestic market situation. Secondly, it is possible to cooperate with universities to train talents in long-term rental apartments in colleges and universities, and apartment enterprises can provide corresponding internship positions for college students. Finally, enterprises should improve the personnel training mechanism, conduct regular training and assessment for employees, disseminate corporate culture, and enhance employees' corporate identity.

\section{E. Expanding Financing Channels}

Relevant departments should actively improve the financial system and provide policy support to the long-term rental apartment industry, such as breaking through the limit of possible existence of light assets and no hard mortgages of the apartment industry, and encouraging financial institutions to implement the bank credit financing model for long-term rental apartment institutions. In addition, learn from foreign experience, implement projects such as REITs, provide financing facilities, and reduce financing costs. Improve the financial system and expand financing channels.

\section{CONCLUSION}

In the economically developed first-tier cities, due to the large number of migrants, the housing problem has become an important issue affecting urban development. This paper analyzes the factors affecting the development of long-term rental apartments, such as the market, society and policies, finds out the problems encountered in the development and management of long-term rental apartments, and proposes solutions from the five aspects of establishing a unified management system, rationally reducing operating costs, seeking new profit models, expanding talent recruitment channels, and expanding financing channels.

\section{REFERENCES}

[1] Liu Zhuo. Thoughts and Suggestions on the Development of China's Long-term Rental Apartment Market[J]. Informatization of China Construction, 2017. (3)

[2] Li Fengqin. Research on the Ways to Realize the Target of Creating a Safe Environment in Enterprise Apartment Management[J]. Reform and Opening, 2010.(1)

[3] Wang Jianhong. Research on the status quo, problems and countermeasures of the development of long-term rental apartment industry [J]. Residential and Real Estate, 2016.(11)

[4] Meng Ruiqi. Research on REIT in Long-term Rental ApartmentsTaking CYPA as an Example[J].Anjia,2017.(3)

[5] Liu Yasai. The operation mode of long-term rental apartments in Japan [J]. China Real Estate, 2017. (12)

[6] Yang Xianling. Wang Aoye. EQR: The American apartment operator with 30 billion market value[J]. China Real Estate, 2015. (5) 